Hiliel I. Kashtan MD, Andrew Maitland MD FRCs, Tomas A. Salerno MD, FRCs, Samual V. Lichtenstein MD FRCS, Robert J. Byrick MD, FRCPC

\title{
Effects of tricuspid regurgitation on thermodilution cardiac output: studies in an animal model
}

\begin{abstract}
The thermal dilution technique (TD) of measuring cardiac outpui ( $\dot{Q}$ ) has been assumed to be inaccurate when the tricuspid valve is regurgitant (TR). The indicator transit time from the right atrium to pulmonary artery $(P A)$ is prolonged and may increase indictor loss to the heart and adjacent tissue. We surgically created TR in four anaesthetized dogs and compared simultoneous cardiac output measurement made with an implanted PA fow probe with intermittent TD cardiac output measurements. We found an excellent correlation $(r=0.98)$ besween the vechniques in the normal heart when $\dot{Q}$ was increased by 100-150 per cent of control values using an intravenous dobutamine infusion. After $T R$ was produced by incorporating the tricuspid valve leaflet within a suture, $\dot{Q}$ decreased. Dextran 40 was then infused and $\dot{Q}$ increased significantly. The rate at which $\dot{Q}$ increased was greater with the TD technique than with the PA flow prabe ; however, a significant ( $r=0.85$ ) linear relationship was still present with $T R$. The altered thermal waveform detected by the $P A$ thermistor in $T R$ was characterized by a lower peak amplifude and a slower return to baseline. Within the limitations of an animal moded, our data suggest that TD cardiac output may be more accurate than previously assumed, particularly in low output states.
\end{abstract}

\section{Key words}

MEASUREMENT: cardiac output; TECHNIQUES: thermodilution cardiac output; HEART: tricuspid regurgitation.

From the Departments of Anaesthesia and the Division of Cardiovascular and Thoracic Surgery, University of Toronto, St. Michael's Hospital, Toronto.

This study was supported by a grant from the Heart and Stroke Foundation of Ontario.

Address correspondence to: Dr. R.J. Byrick, Department of Anaesthesia, St Michael s Hospital, 30 Bond Street, Toronto, Ontario M5B 1 W8.
Thcrmodilution (TD) cardiac output measurement has become an established technique in critical care and in the operating room. ${ }^{1-3}$

Sources of error in the calculation of cardiac output by TD have been analyzed..$^{4-8}$ In tricuspid insufficiency, the thermodilution technique has been assumed to be inaccurate, ${ }^{2,5,6.8}$ with the Fick method being more reliable. The abnormal mixing of blood with injectate solution and indicator temperature loss to adjacent tissue secondary to bidirectional flow from the right ventricular cavity is the proposed cause of this inaceuracy. If surrounding tissue fails to release this cold injectate prior to completion of the thermodilution curve integration, indicator will not be detected by the pulmonary artery thermistor and cardiac output would be overestimated.

The purpose of this investigation was to assess the accuracy of thermodilution cardiac output measurements in experimentally produced tricuspid regurgitation (TR) by comparison with measured pulmonary artery flow. The thermodilution curves were further analyzed independently to determine how a standard cardiac output computer (American Edwards) functions in this condition.

\section{Methods}

Four unpremedicated mongrel dogs (weight $20-22.5 \mathrm{~kg}$ ) were anaesthetized with intravenous pentobarbitone $(30 \mathrm{mg}$. $\mathrm{kg}^{-1}$ ). After loss of consciousness, oral endotracheal intubation was performed. Anaesthesia was then maintained by intravenous pentabarbitone infusion ( $100 \mathrm{mg} \cdot \mathrm{h}^{-1}$ ). Each animal was paralyzed with pancuronium, $5 \mathrm{mg}$ intravenously, and mechanically ventilated (Bennett MA-1) with 100 per cent oxygen to maintain an arterial $\mathrm{PCO}_{2}$ of $35-40 \mathrm{mmHg}$.

Aortic arterial pressure (BP) was measured by a 16 gauge cannula inserted via the femoral artery. Through the left femoral vein a \#7 Fr pulmonary artery (flow directed) thermodilution catheter was positioned for monitoring of pulmonary artery pressure (PAP), wedge pressure (PCWP), as well as cardiac output. A left thoracotamy was then performed with dissection and placement 


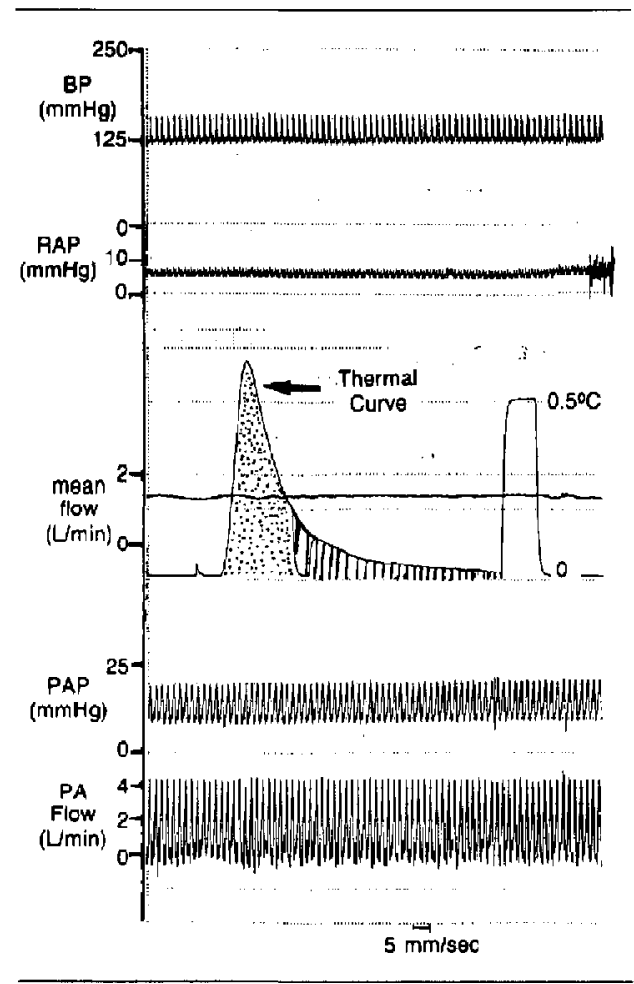

FIGURE 1 A sample trace in one dog of arterial blood pressure (BP), right alrial (RAP) and pulmorlary artery (PAP) pressures, PA flow using an implanted fow probe and the thermal dilution curve in the control state.

of a calibrated electromagnetic flow probe, appropriate for size, on the main pulmonary artery (Micron MedicalRC 2000 Blood Flow Computer).

Following the above procedures, a purse string suture was placed around the right atrial appendage and an atriotomy performed. A finger was inserted through the atrial appendage and the tricuspid valve was palpated. Two sutures of 0 silk were placed from the right ventricular side to incorporate the tricuspid leaflet and chordae tendinae; both ends of the suture then lying externally were snared with a tourniquet. Tricuspid incompetence with regurgitation could be produced by applying traction and tightening the tourniquet. At this point an atrial thrill was palpable (see Figures 1 and 2 for simultaneous tracings of RA, PA, BP and PA flow).

A second pulmonary artery catheter, cut at the $30 \mathrm{~cm}$ proximal port, was placed under direct vision through the atrial purse-string into the right atrium for both mea-

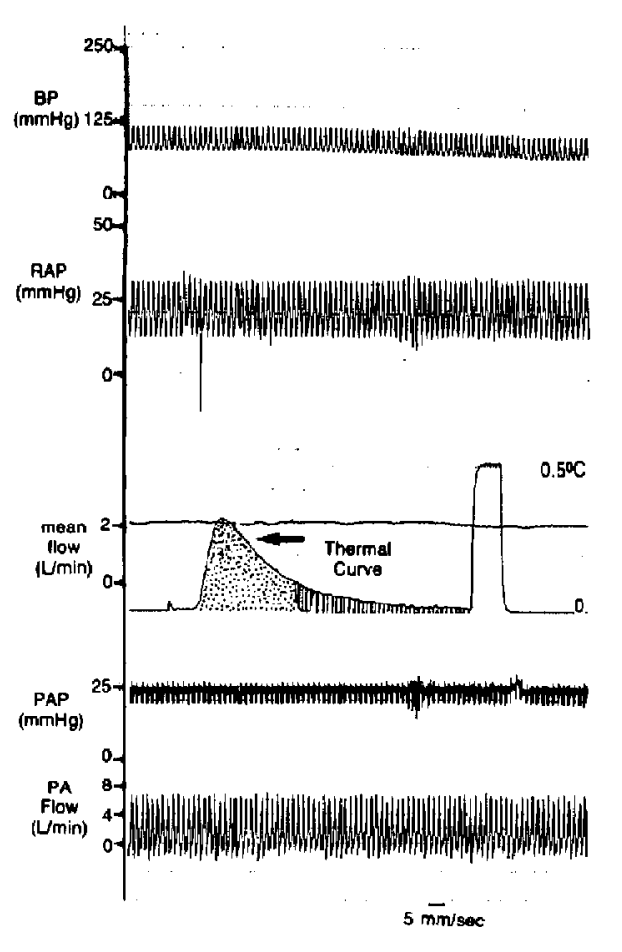

FIGURE 2 A sample trace in another dog of arterial blood pressure (BP), right atrial (RAP) and pulmonary artery (PAP) pressures, PA flow and themal dilution curve after tricuspid regurgitation was produced and dextran administered to raise cardiac output.

surement of atrial pressure (RAP) and injection of room temperature five per cent dextrose in water (D5W). Five millilitre aliquots of D5W, with the appropriate computation constant, were injected directly into the right atrium for determination of cardiac output, and the corresponding thermodilution curves (Amcrican Edwards $9520 \mathrm{~A}$ cardiac output) were recorded (Figure 1). All cardiac output measurements were initiated during apnoea, at end expiration. This second catheter was used for injecting the indicator to ensure a correct injection site without altering catheter (injectate) volume.

Three baseline measurements of pulmonary artery pressure, pulmonary capillary wedge pressure, right atrial pressure, pulmonary artery flow, cardiac output and thermodilution curves were recorded on a Gould ES-1000 recorder at $5 \mathrm{~mm} \cdot \mathrm{sec}^{-1}$ paper speed (Figure 1). The above parameters were again recorded aftcr infusion of dobutamine to increase cardiac output in this control 
TABLE

\begin{tabular}{|c|c|c|c|}
\hline & Control & $\begin{array}{l}\text { Tricuspid } \\
\text { regurgitation }\end{array}$ & $\begin{array}{l}\text { Tricuspid } \\
\text { regurgitation } \\
+ \text { dextran }\end{array}$ \\
\hline $\mathrm{PAQ}\left(\mathrm{L} \cdot \min ^{-1}\right)$ & $2.27 \pm 1.38$ & $1.42=0.36^{*}$ & $2.51 \pm 0.48 \dagger$ \\
\hline$\dot{Q}\left(L \cdot \min ^{-1}\right)$ & $2.90 \pm 1.10$ & $1.56 \pm 0.45^{*}$ & $2.89 \pm 0.66 \dagger$ \\
\hline$\overline{\mathrm{RAP}}(\mathrm{mmHg})$ & $4.94 \pm 1.35$ & $7.22 \pm 2.76$ & $14.87 \pm 3.35 \dagger$ \\
\hline$(\mathrm{kPa})$ & $0.66 \pm 0.18$ & $0.96=0.37$ & $1.97 \pm 0.45$ \\
\hline$\overline{\mathrm{PAP}}(\mathrm{mmHg})$ & $19.36 \pm 2.98$ & $15.61 \pm 2.01^{*}$ & $20.30 \pm 3.63 \dagger$ \\
\hline$(\mathrm{kPa})$ & $2.57 \pm 0.39$ & $2.08 \pm 0.27$ & $2.69 \pm 0.48$ \\
\hline$\overline{\mathrm{BP}}(\mathrm{mmHg})$ & $129.64 \pm 8.83$ & $91.28 \pm 23.77^{*}$ & $112.05 \pm 21.64 \dagger$ \\
\hline$(\mathrm{kPa})$ & $16.71 \pm 1.17$ & $12.14 \pm 3.16$ & $14.90 \pm 2.88$ \\
\hline
\end{tabular}

*Indicates significant difference from control value $(p<0.05)$. tIndicates significant difference from tricuspid tegurgitation value ( $\mathrm{p}<0.05$ ) vs TR and dextran.

Values are reported as mean \pm SD.

state $100-150$ per cent as measured by the PA flow probe.

Tricuspid regurgitation was subsequently produced and similar measurements taken in the normovolaemic and fluid loaded states (ten per cent dextran 40 in nomal saline, $250-500 \mathrm{ml}$ ). Cardiac output was increased for control measurements by dobutamine because of its brief duration and reversibility and the need to study the effects of TR at low as well as high outputs. After TR was produced, higher cardiac output and presumably regurgitant fraction could be produced by intravascular volume expansion with dextran 40 . After all measurements were recorded each animal was killed by IV injection of potassium chloride.

Analysis of the area under the thermodilution curves were determined using manual planimetry, with the average of three planimetry readings calculated for each curve. Two areas on each time-temperature curve were determined (Figure 1): (1) the area (A) prior to the cut-off point utilized by the cardiac output computer which calculates, by extrapolation, the area under the curves; (2) the total area calculated manually from the thermodilution curve (represented in Figure 1 by $A$ and B).

Data are reported as mean $\pm S D$. Differences between pre TR (control) and post TR values were analyzed using a two-way analysis of variance and Dunnett's multiple range test. When $p<0.05$, the differences were considered significant. Linear regression was performed comparing simultancous thermal dilution and PA flow measurements. Differences in slopes of linear regression were compared with the line of identity.

\section{Results}

Tightening the right ventricular sutures produced statistically significant reductions of pulmonary artery flow,

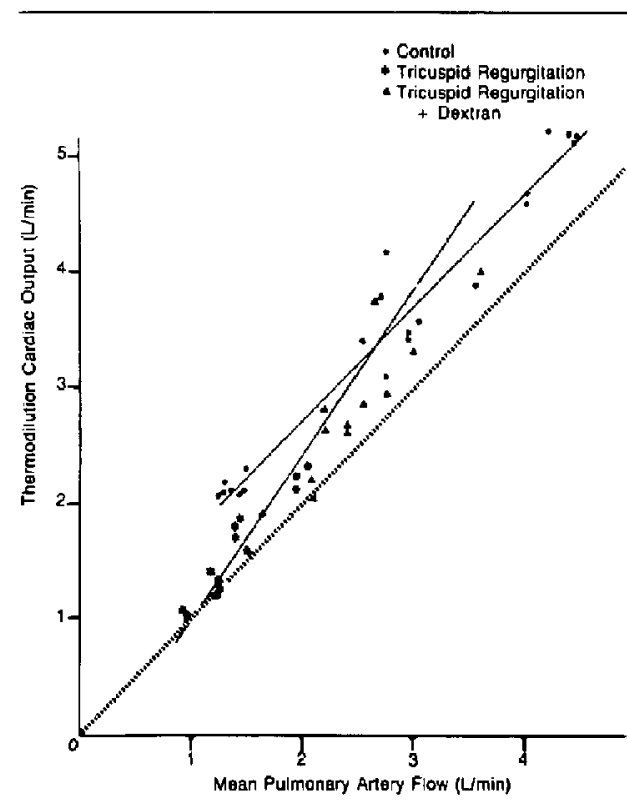

FIGURE 3 Simultaneous measurements of cardiac output measured by the thernodilution techrique plotted with measurements made using the implanted PA How probe. Valucs made prior to creating TR are denored with a (controls include dobulanine-induced increases in $Q$ ). Values after creating TR are represented by a $*$ and with TR and dexiran by a $\boldsymbol{\alpha}$.

thermodilution calculated cardiac output, BP and PAP $(p<0.05)$ (Table). Mean right atrial pressures were elevated in the tricuspid regurgitation group, as compared to control, but statistical significance was only attained after dextran infusion. The right atrial ' $v$ ' waves observed in Figure 2 further confirm the presence of tricuspid valve incompetence; but, due to the nature of the technique, the degree of regurgitation varied between animals.

A significant linear relationship was present when pulmonary artery flow, an independent measure of right ventricular cardiac output, was plotted against thermodilution calculated cardiac output (Figure 3). Comparison of the lines of tegression in control and tricuspid regurgitation groups (Figure 3 ) produced correlation coefficients of 0.98 and 0.85 respectively. The slopes of regression were 0.98 in the control state and 1.44 with TR. The difference in slopes between control and TR measurements was significant $(p<0.05)$. The slope of the line of regression for TR was significantly different from the line of identity $(p<0.05$ ) (Figure 3), whereas that of the control group was not.

Figure 2 illustrates the alteration of thermodilution 
curve waveform after production of TR. The upstroke and downstroke are both prolonged with a reduction of peak curve amplitude as compared to the control curve. Mathernatical analysis by planimetry, measuring area $\mathrm{A}$ (Figure 1, area under the curve used in the calculation of cardiac output) in relation to total area $(A+B)$, was expressed as a percentagc. The ratio of area $\mathrm{A} / \mathrm{A}+\mathrm{B}$ was significantly less $(71 \pm 3$ per cent) in the resting state than in the TR group $(80 \pm 6$ per cent) (Figure 4$)$ ( $p$ $<0.001$ ). In both groups the amplitude of temperature waveform (Figure 2) at termination of the computer analysis (cut-off point), equalled approximately 33 per cent of the peak height.

\section{Discussion}

The measurement of blood flow by thermodilution utilizes the Steward-Hamilton equation. ${ }^{7}$ Modifications of the formula are required to correct for parameters affecting temperature. These adjustments include specific heat and specific gravity of both blood and injectate solution. As well, a correction factor for injectate warming (i.e., along the catheter) is also necessary. The modified equation is presented:

$$
\mathrm{CO}=\mathrm{V} \times \frac{\left(\mathrm{T}_{\mathrm{B}}-\mathrm{T}_{1}\right)}{\mathrm{A}} \times \frac{\left(\mathrm{S}_{\mathrm{I}} \times \mathrm{C}_{1}\right)}{\left(\mathrm{S}_{\mathrm{B}} \times \mathrm{C}_{\mathrm{B}}\right)} \times(60 \times \mathrm{C} \times \mathrm{K})
$$

where

$$
\mathrm{CO}=\text { cardiac output, } \mathrm{L} \cdot \min ^{-1}
$$$$
\mathrm{V}=\text { volume of injectate }
$$

$T_{B}, T_{I}=$ temperature of blood and injectate

$S_{B}, S_{I}=$ specific gravity of blond and injectate

$C_{B}, C_{1}=$ specific heat of blood and injectate

$A=$ area under the curve

$\mathrm{C}=$ correction factor for warming of injectate

$\mathrm{K}=$ calibration constant, $\mathrm{mm} / \mathrm{C}$

$60=\sec / \mathrm{min}$

There are minimal differences in specific heat and specific gravity between normal saline and DSW: $1.10 \mathrm{vs}$ 1.08 respectively. ${ }^{7}$ The volume of injectate chosen for this study was $5 \mathrm{ml}$ of D $5 \mathrm{~W}$. Injectate temperature $\left(22-25^{\circ} \mathrm{C}\right.$ ) and blood temperature remained constant during each measurement. The correction factor takes into consideration injection rate, heat change in transit, catheter dead space, and is calculated for each computer model by the manufacturer. Therefore, in our measurement of $\dot{Q}$ during TR these variables were maintained constant, with the exception of area under the curve - which is computed from temperature change detected by the thermistor.

Experimental ertor in our TD measurements of $\dot{Q}$ was minimized in several ways. First, all injections and curves were initiated during apnoea at end-expiration since me-

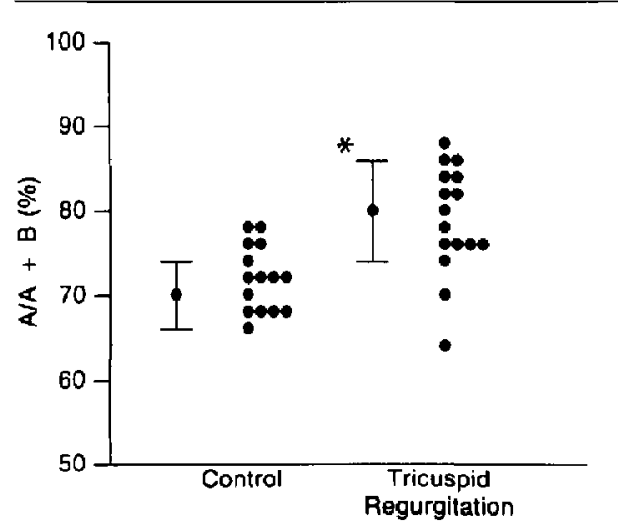

FIGURE 4 The area under the thermodilution curve used by the com. puter in calculate $Q$ (area $A$ - Figures $2 a, 2 b$ ) as a percentage of the total area under the curve (area $\mathrm{A}+\mathrm{B}$, Figures $2 \mathrm{a}$ and $2 \mathrm{~b}$ ).

chanical ventilation affects cardiac output by altering preload, afterload, ventricular geometry ${ }^{4,9,10}$ and by producing variations in pulmonary artery temperatures in relation to respiration. ${ }^{10-14}$ Second, the D5W was injected through a second catheter (Swan-Ganz), cut at $30 \mathrm{~cm}$, inserted directly into the right atrium, to ensure correct right atrial injcetion site without altering catheter volume or length as well as use of an appropriate correction factor. Runciman $e t a l .{ }^{15}$ demonstrated the inaccuracy of utilizing inferior vena caval injections which results in increased loss of indicator (calories) to adjacent tissue.

The presence of surgically produced TR was confimed by several techniques. After tightening both sutures encircling the chordae tendinae, an atrial thrill was palpable. Right atrial tracings presented in Figures 1 and 2 show the large atrial ' $v$ ' waves associated with this condition. In the TR group mean right atrial pressure was elevated compared to control, but not to a statistically significant level; although there were associated statistically significant reductions of all other haemodynamic parameters measured (Table). Tightening these sutures caused physical displacement of the tricuspid leaflets by pulling the chordae and leaflets. Therefore the reduction in $\dot{Q}$ (Table) was probably secondary to valvular incompetence. The degree of TR and $\dot{Q}$ both increased after dextran infusion (Table). Although TR was created with this technique, the degree of regurgitation could not be standardized or controlled.

A significant correlation (Figurc 3) was present between PA flow and thermodilution cardiac output ${ }^{15,17}$ in the range of outputs measured in this experiment. Therefore, previous assumptions regarding the assumed inac- 
curacy of the thermodilution technique with $\mathrm{TR}^{2,5,18}$ may not be clinically valid especially in low output states. We observed (Figure 3) a greater discrepancy between PA fow and TD cardiac output at high Q states with TR. This error which has been assumed to be present $^{2,5,6,8}$ may have been caused by increased TR at the high cardiac output state generated by dextran volume loading. This would result in a prolongation of the indicator transit time in the right heart with an increase in indicator loss to the adjacent tissue. When higher $\dot{Q}$ is combined with severe $T R$ the values obtained may be inaccurate to a greater degree. This would explain the significant deviation of our linear regression (Figure 3 ) from one in the presence of TR and dextran volume loading. It is important to note that in atl cases of volume loading, regardless of the altered degree of regurgitation, the directional change of $\mathrm{TD}$ calculated $\dot{Q}$ was always correct.

Analysis was undertaken to determine the waveform alteration with TR and the area under the curve utilized in computing cardiac output. Our planimetry data (Figure $1,2)$ confirm the changes observed in previous clinical and experimental modes. ${ }^{2,5.18}$ The waveform is splayed, both upstroke and downstroke being prolonged, combined with a reduction of peak amplitude.

This cardiac output computer incorporates the automatic termination of thermistor recordings at 30 per cent of the peak amplitude. ${ }^{18}$ Clinical studies have shown that the area lost after termination (tail of TD curve) is equal to approximately 22 per cent (area B) of total area. To compensate, the computer software amplifies the input signal (area A) by this factor (1.22) to approximate the total area under the curve (area $A+B$, Figure 1). Planimetry measurements of the TD curves indicated that this assumption held true for tricuspid incompetence (the areas in this experiment were raw curves and not subjected to an amplification factor). In the control group the percentage area lost as a result of this automatic termination was $29 \pm 3$ per cent. This is 9 per cent above experimental studies and may account for the slight increase in TD cardiac output values relative to the $\dot{Q}$ measured with the flow probe. The lines of regression for control values and the line of identity (Figure 3) were parallel and not significantly different, indicating that this factor was not producing large deviations in control TD values. Other possible explanations include the increased loss of area secondary to cutoff at 33 per cent of peak height or a slightly inaccurate amplification factor. Control values maintained a straight line relationship in the range studied; therefore this error in area calculation was constant for all measurements.

In summary, the key factor explaining the degree of accuracy in experimentally produced TR was the altered
TD waveform. Lowering the peak amplitude and slowing the downward trend of temperature change in TR caused a delay in the cutoff point with this computer, thus maintaining the accuracy of the calculated area under the curve. This serves to emphasize that the clinician must know how the TD curve is manipulated by the computer, if the effects of TR and other defects on the TD measurements are to be understood. In view of the small number of experimental animals (four) and our inability to quantify the degree of $T R$, these data need to be reassessed in the clinical situation.

Under altered clinical conditions (e.g., increased pulmonary vascular resistance, or poor right ventricular contractility) the time-temperature waveform may be altered to a greater degree, with a corresponding reduced accuracy of TD calculated cardiac output. This is a major limitation in extrapolating our data to the clinical situdtion as our dogs had nomal ventricular function and pulmonary vascular resistance (PVR). Many patients with TR have elevated PVR and reduced right ventricular function which would delay TD transit time even further and might cause further aberrations in the TD cardiac output calculation.

Considering these limitations and the 2-15 per cent $^{19,20}$ inaccuracy inherent in the TD technique, the derived cardiac output appeared more accurate than previously assumed in isolated tricuspid regurgitation especially in low output states.

\section{Acknowledgements}

The authors wish to thank Mr. J. Colin Kay and Mrs. D. Forbes for technical assistance, and Pat Slusarenko and Dr. J. Abel for preparation and review of the manuscript. This study was supported by a grant from the Heart and Stroke Foundation of Ontario.

\section{References}

1 Stetz W, Miller RG, Kelly GF et al. Reliability of the thermodilution method in the determination of cardiac output in clinical practice. Am Rev Respir Dis 1982; 126 1001-4.

2 Olsson B, Pool J, Vandermoten $P$ et al. Validity and reproducibility of determination of cardiac output by thermodilution in man. Cardiology 1970; 55: 136-48.

3 Ganz W, Donoso R, Marcus HS, Forrester IS, Swan HJC. A new technique for measurement of cardiac output by thermodilution in man. Am J Cardiol 1971; 27: 392-6.

4 Levert $J M$, Replogle $R L$. Thermodilution cardiac output: a critical analysis and review of the literature. J Surg Res 1979; $27: 392-404$.

5 Fischer AP, Benis AM, Jurado RA et al. Analysis of errors in measurement of carcliac output by simultaneous dye and 
thermal dilution in cardiothoracic surgical patients. Cardiovascular Research 1978; 12: 190-9.

6 Edwards Laboratories: Understanding hemodynamic measurements made with the Swan-Ganz catheter. Santa Ana Calif.

7 Gonz W, Swan HJ. Measurement of blood flow by thermodilution. Am J Cardiol 1972; 29 : 241-6.

8 Ohteki $\mathrm{H}$, Nagara H, Wada J et al. Measurements of cardiac output by thermodilution and Fick method in man. Kokyu to Junkan $1981 ; 29: 433-7$.

9 Afonso S, Herrick JF, Youmans WB, Rowe GG. Crumpton $C W$. Temperature variations in the venous systems in dogs. Am J Physiol 1962; 203: 278-82.

10 Stevens J, Raffin $T$, Mihm $F$ et ul. Thernodilution cardiac output measurement: eflects of the respiratory cycle on its reproducibility. JAMA $1985 ; 253 ; 2240-2$.

11 Wessei $H U$, James $G W$, Paul MH. Effects of respiration and circulation on central temperature of the dog. Am J Physiol 1966;2111: 1403-12.

12 Woods $M$, Scott $R W$, Harken $A H$. Practical considerations for the use of a pulmonary artery thermistor catheter. Surgery 1976; $79: 469-75$.

13 Wessel HU, Pahl MH, James GW. Limitations of thermal dilution curves for cardiac output determination. J Appl Physiol 1971; 30: 643-52.

14 Amengol J, Man GC, Balsys $A J$ et al. Effects of the respiratory cycle on cardiac output measurements: reproducibility of data enhanced by timing the thermodilution injections in dogs. Crit Care Med 1981; 9: 852-4.

15 Runciman WB, Isley $A H$, Roberts JG. Thermodilution cardiac output: a systemic error. Anaesth Intensive Care 1981; $9: 135-9$.

16 Meisner H, Hagl $S$, Heimisch $W$ et al. Evaluation of the thermodilution method for measurement of cardiac output after open heart surgery. Ann Thorac Surg 1974; 18: 504.

17 Beyer J, Lambert JJ, Keplogle RL. Validity of thermodilution cardiac output determination: expcrimental studies with and without pulmonary insufficiency. J Surg Res 1976: 21 : 313-7.

18 American Edwards Laboratory. Cardiac Output Computer, Operations and Field Manuat, Model 9520, Santa Ana, Calif. 1977.

19 Forrester JS, Ganz W, Diamond $G$. Thermodilution cardiac output determination with a single flow-directed catheter. Am Heart J 1972; 83; 306-11.

20 Weisei RD. Berger RL, Hechtman HB. Measurcment of cardiac output by thermodilution. N Engl J Med 1975; 292 : 682-4.

\section{Résumé}

Les iechniques de thermodilution (TD) pour la mesure du débit cardiaque $(\dot{Q})$ ont été assumées pour être inexactes en présence d'une régurgitation de la valve tricuspide (TR). Le temps de transit de l'indicateur de l'oreillette droite à l'artère pulmonaire (PA) est prolongé er peut augmenter les pertes de l'indicateur vers le caur es les tissus adjacents. On a créé chirurgicalement une régurgitation tricuspidienne (TR) chez quatre chiens anesthésiés et or a comparé simultanément les débits cardiaques avec ceux obtenus par un détecteur de flot implanté autour de lartère pulmonaire. On a trouvé une excellente corrélation ( $r=0.98$ ) entre les techniques chez le craur normal quand le débit cardiaque fut angmenté de 100-150 pour cent des valeurs de contrôle suite da la perfusion intraveineuse de dobutamine. Après la création d'une régurgitation tricuspidienne par suture des feuillets de la valve rricuspide le débit cardiaque diminua. Du dextran 40 a été administré et le débu cardiaque augmenta significativement. Le taux auquel le débit cardiaque augmenta était plus grand avec la technique de thermodilution qu'avec les mesures du flot dans l'artère pulmonaire. Cependant une corrélation tinéaire significative ( $r=$ $0.85)$ ésait encore présente en présence de la régurgitarion tricuspidicnne. Lors de la régurgitation tricuspidienne, la courbe altérée obtenue par la technique de thermodilution était caractérisée par un maximum d'amplitude plus bas et un retour plus lent a la ligne de bas. Avec les limitations du modèle animal, nos données suggèrent que le débit cardiaque obtenu par thermodilution peut être plus exact que ce qu'on avait déjà assumé au préalable et ce particulièrement dans les éluts de bas débits. cardiaques. 